\title{
Apocynin Exerts Dose-Dependent Cardioprotective Effects by Attenuating Reactive Oxygen Species in Ischemia/Reperfusion
}

Qian Chen, Woodworth Parker C, Issachar Devine, Regina Ondrasik, Tsion Habtamu, Kyle D Bartol, Brendan Casey, Harsh Patel, William Chau, Tarah Kuhn, Robert Barsotti and Lindon Young*

Department of Bio-Medical Sciences, Philadelphia College of Osteopathic Medicine, Philadelphia, USA

\begin{abstract}
Ischemia/reperfusion results in cardiac contractile dysfunction and cell death partly due to increased reactive oxygen species and decreased endothelial-derived nitric oxide bioavailability. NADPH oxidase normally produces reactive oxygen species to facilitate cell signalling and differentiation; however, excessive release of such species following ischemia exacerbates cell death. Thus, administration of an NADPH oxidase inhibitor, apocynin, may preserve cardiac function and reduce infarct size following ischemia. Apocynin dose-dependently $(40 \mu \mathrm{M}, 400 \mu \mathrm{M}$ and 1 $\mathrm{mM}$ ) attenuated leukocyte superoxide release by $87 \pm 7 \%$. Apocynin was also given to isolated perfused hearts after ischemia, with infarct size decreasing to $39 \pm 7 \%(40 \mu \mathrm{M}), 28 \pm 4 \%(400 \mu \mathrm{M} ; \mathrm{p}<0.01)$ and $29 \pm 6 \%(1$ $\mathrm{mM} ; \mathrm{p}<0.01$ ), versus the control's $46 \pm 2 \%$. This decrease correlated with improved final post-reperfusion left ventricular end-diastolic pressure, which decreased from $60 \pm 5 \%$ in control hearts to $56 \pm 5 \%(40 \mu \mathrm{M}), 43 \pm 4 \%$ $(400 \mu \mathrm{M} ; \mathrm{p}<0.01)$ and $48 \pm 5 \%(1 \mathrm{mM} ; \mathrm{p}<0.05)$, compared to baseline. Functionally, apocynin $(13.7 \mathrm{mg} / \mathrm{kg}$, I.V.) significantly reduced $\mathrm{H}_{2} \mathrm{O}_{2}$ by nearly four-fold and increased endothelial-derived nitric oxide bioavailability by nearly four-fold during reperfusion compared to controls $(p<0.01)$, which was confirmed in in vivo rat hind limb ischemia/reperfusion models. These results suggest that apocynin attenuates ischemia/reperfusion-induced cardiac contractile dysfunction and infarct size by inhibiting reactive oxygen species release from NADPH oxidase.
\end{abstract}

Keywords: NADPH oxidase; Apocynin; Myocardial ischemia/ reperfusion; Hind limb ischemia/reperfusion; Nitric oxide; Hydrogen peroxide; Leukocyte superoxide release

\section{Introduction}

Coronary heart disease is the leading cause of death worldwide [1]. The most effective therapeutic intervention for reducing infarct size associated with myocardial ischemic injury is timely and effective reperfusion of blood flow back to the heart tissue by percutaneous coronary intervention. However, the reperfusion of blood itself can induce additional cardiomyocyte death that can account for up to $50 \%$ of the final infarct size [2]. Remarkably, after several decades of preclinical and clinical studies, there is still no effective therapy to limit reperfusion-induced tissue death and improve post-reperfused cardiac function. Consequently, there is a great need to identify the mechanism(s) responsible for myocardial ischemia/reperfusion injury.

Ischemia/reperfusion injury is initiated in part by endothelial dysfunction, which occurs within 5 min of reperfusion. It is characterized by an increase in reactive oxygen species leading to endothelial nitric oxide synthase uncoupling, which in turn causes more reactive oxygen species production and limited endothelial-derived Nitric Oxide (NO) bioavailability [2-4]. The reduced NO bioavailability leads to compromised blood flow during reperfusion and increased leukocyteendothelial interactions, which will exacerbate tissue damage. The time course of endothelial dysfunction in myocardial ischemia/reperfusion is similar to other vascular beds, such as hind limb ischemia/reperfusion and splanchnic ischemia/reperfusion $[5,6]$. The significance of this commonality is that compounds that attenuate endothelial dysfunction in the heart could be applied to other vascular beds such as pulmonary, kidney, liver, mesenteric and limb circulation. Therefore, this could be clinically applied to prevent organ damage in various ischemia/ reperfusion injury settings, such as organ transplantation, circulatory shock, prolonged tourniquet use and coronary bypass/balloon angioplasty.

In order to understand endothelial dysfunction during ischemia/ reperfusion, we established an in vivo rat hindlimb ischemia/ reperfusion injury model that directly measures reactive oxygen species levels in blood (i.e., hydrogen peroxide $\left[\mathrm{H}_{2} \mathrm{O}_{2}\right]$ ) and $\mathrm{NO}$ in real-time $[4,7,8]$ from both femoral veins (with one limb subjected to ischemia/ reperfusion and the other serving as a sham control). $\mathrm{H}_{2} \mathrm{O}_{2}$ is an indirect index of superoxide $(\mathrm{SO})$ release because $\mathrm{SO}$ dismutase rapidly, within seconds, converts $\mathrm{SO}$ to $\mathrm{H}_{2} \mathrm{O}_{2}$; this process is enhanced under low $\mathrm{pH}$ conditions $[9,10]$. Our hind limb ischemia/reperfusion injury model is appropriate to measure $\mathrm{H}_{2} \mathrm{O}_{2}$ and $\mathrm{NO}$ blood levels during ischemia/ reperfusion because the direct measurements are not feasible in the coronary circulation of the isolated perfused rat heart model. We found that an inverse relationship exists between blood $\mathrm{H}_{2} \mathrm{O}_{2}$ and $\mathrm{NO}$ levels in ischemia/reperfusion. Greater production of $\mathrm{H}_{2} \mathrm{O}_{2}$ and reduction of NO during reperfusion in hind limb ischemia/reperfusion closely correlates with a greater degree of post-reperfused cardiac dysfunction in myocardial ischemia/reperfusion $[4,7,8]$.Therefore, quantifying blood reactive oxygen species release and NO levels in real-time during reperfusion is important to determine the initiating sources of reactive oxygen species in ischemia/reperfusion and to develop potential treatment strategies for ameliorating reperfusion injury.

Although clinical trials suggest non-selective antioxidants do not effectively attenuate reperfusion injury, this may be due to lack of

*Corresponding author: Lindon Young, Department of Bio-Medical Sciences, Philadelphia College of Osteopathic Medicine (PCOM), 4170 City Avenue, Philadelphia, USA, Tel: 2158716832; Fax: 2158716869; E-mail: Lindonyo@PCOM.edu

Received February 16, 2016; Accepted February 24, 2016; Published March 01 2016

Citation: Chen Q, Parker WC, Devine I, Ondrasik R, Habtamu T, et al. (2016) Apocynin Exerts Dose-Dependent Cardioprotective Effects by Attenuating Reactive Oxygen Species in Ischemia/Reperfusion. Cardiovasc Pharm Open Access 5: 176. doi:10.4176/2329-6607.1000176

Copyright: ( 2016 Chen Q, et al. This is an open-access article distributed under the terms of the Creative Commons Attribution License, which permits unrestricted use, distribution, and reproduction in any medium, provided the original author and source are credited. 
Citation: Chen Q, Parker WC, Devine I, Ondrasik R, Habtamu T, et al. (2016) Apocynin Exerts Dose-Dependent Cardioprotective Effects by Attenuating Reactive Oxygen Species in Ischemia/Reperfusion. Cardiovasc Pharm Open Access 5: 176. doi:10.4176/2329-6607.1000176

Page 2 of 7

specifically targeting the source of oxidative stress. Four enzymatic sources principally contribute to oxidative stress (i.e., reactive oxygen species) during reperfusion: NADPH oxidase, xanthine oxidase, uncoupled eNOS, and the mitochondrial electron transport chain. NADPH oxidases comprise a family of enzymes that initiates and recruits the other three sources as follows [11]: 1. NADPH oxidase 2 (Nox2) naturally produces $\mathrm{SO} / \mathrm{H}_{2} \mathrm{O}_{2}$ upon the assembly of the cytosolic subunits (i.e., rac, p67 phox $\mathrm{p} 47^{\text {phox }}$, and $\mathrm{p} 40^{\text {phox }}$ ) with, the membrane subunits (i.e., p22 $2^{\text {phox }}$ and gp91 ${ }^{\text {phox }}$ ); 2 . It is expressed in many cells in the heart, such as vascular endothelium and cardiac myocytes, and is the principle source of SO release in leukocytes; $3 . \mathrm{SO} / \mathrm{H}_{2} \mathrm{O}_{2}$ release from activated NADPH oxidase can open mitochondrial ATP-dependent potassium channels and/or mitochondria permeability transition pores, which further lead to mitochondrial matrix alkalization, mitochondrial electron transport chain uncoupling, and SO production [12]; 4. Overproduction of $\mathrm{SO} / \mathrm{H}_{2} \mathrm{O}_{2}$ will also promote the transformation of xanthine dehydrogenase into xanthine oxidase $[13,14]$; 5 . SO can quench $\mathrm{NO}$ to form peroxynitrite anion, which in turn can promote eNOS uncoupling via the oxidation of the essential eNOS co-factor tetrahydrobiopterin $\left(\mathrm{BH}_{4}\right)$ to dihydrobiopterin $\left(\mathrm{BH}_{2}\right)$ [15]. It has been found in vitro that the increased ratio of $\mathrm{BH}_{2}$ to $\mathrm{BH}_{4}$ facilitates $\mathrm{BH}_{2}$ binding at the eNOS oxygenase domain, allowing eNOS to use molecular oxygen to produce $\mathrm{SO}$ and, subsequently, $\mathrm{H}_{2} \mathrm{O}_{2}$ in blood [16]. 6. Reactive oxygen species release during reperfusion serves as a key initiating factor that triggers the release of a major inflammatory cytokine, tumor necrosis factor, alpha (TNFa), within the first $15 \mathrm{~min}$ of reperfusion [12,17-20] (Figure 1).

Consequently, inhibition of Nox2 may be an effective strategy to prevent the downstream sequelae of reperfusion injury and salvage heart tissue during myocardial infarction or organ transplantation. Previous studies show apocynin, an alkaloid derived from Apocynum cannabinum, is a selective Nox 2 assembly inhibitor that may oxidize the thiols in NADPH oxidase. Moreover, apocynin may be a prodrug and thus needs to be activated by peroxidase-mediated oxidation to diapocynin, its active oxidizing form, which is illustrated in Figure 2. Specifically, the effects of apocynin oxidize the cysteine-196 position of $4^{4} 7^{\text {hox }}$, a cytosolic component of NADPH oxidase that is activated via phosphorylation by protein kinase $\mathrm{C}$, which, in turn, inhibits the association of the p22 $2^{\text {phox }}$ membrane subunit component of NADPH oxidase and, therefore inhibit Nox2 assembly and subsequent SO release, thereby decreased oxidative stress and tissue damage [21,22].

We hypothesize that administration of selective NADPH oxidase inhibitors, such as apocynin, will dose-dependently attenuate blood $\mathrm{H}_{2} \mathrm{O}_{2}$ and augment $\mathrm{NO}$ bioavailability in hindlimb ischemia/ reperfusion, and will decrease $\mathrm{SO}$ release from leukocytes and reduce infarct size/area-at-risk in ischemia/reperfusion hearts, and thus improving post-reperfused cardiac function.

\section{Methods}

\section{Animals}

All animal procedures were approved by the Institutional Animal Care and Use Committee at PCOM for care and use of animals. Male Sprague Dawley (SD) rats (275-325 g; Ace Animals, Boyertown, PA)

\section{Measurement of SO release from rat PMNs}

The SO release from Poly Morphonuclear Leukocytes (PMNs) was measured spectrophotometrically (model 260 Gilford, Nova Biotech; El Cajon, CA) by the reduction of ferricytochrome $c$ as previously described [23]. The PMNs $\left(5 \times 10^{6}\right)$ were resuspended in $450 \mu \mathrm{l} \mathrm{PBS}$ and incubated with ferricytochrome $\mathrm{c}(100 \mu \mathrm{M}$, Sigma Chemical) in a total volume of $900 \mu \mathrm{PBS}$ in the presence or absence of varying concentrations of apocynin $(\mathrm{MW}=166 \mathrm{~g} / \mathrm{mol}$; Sigma

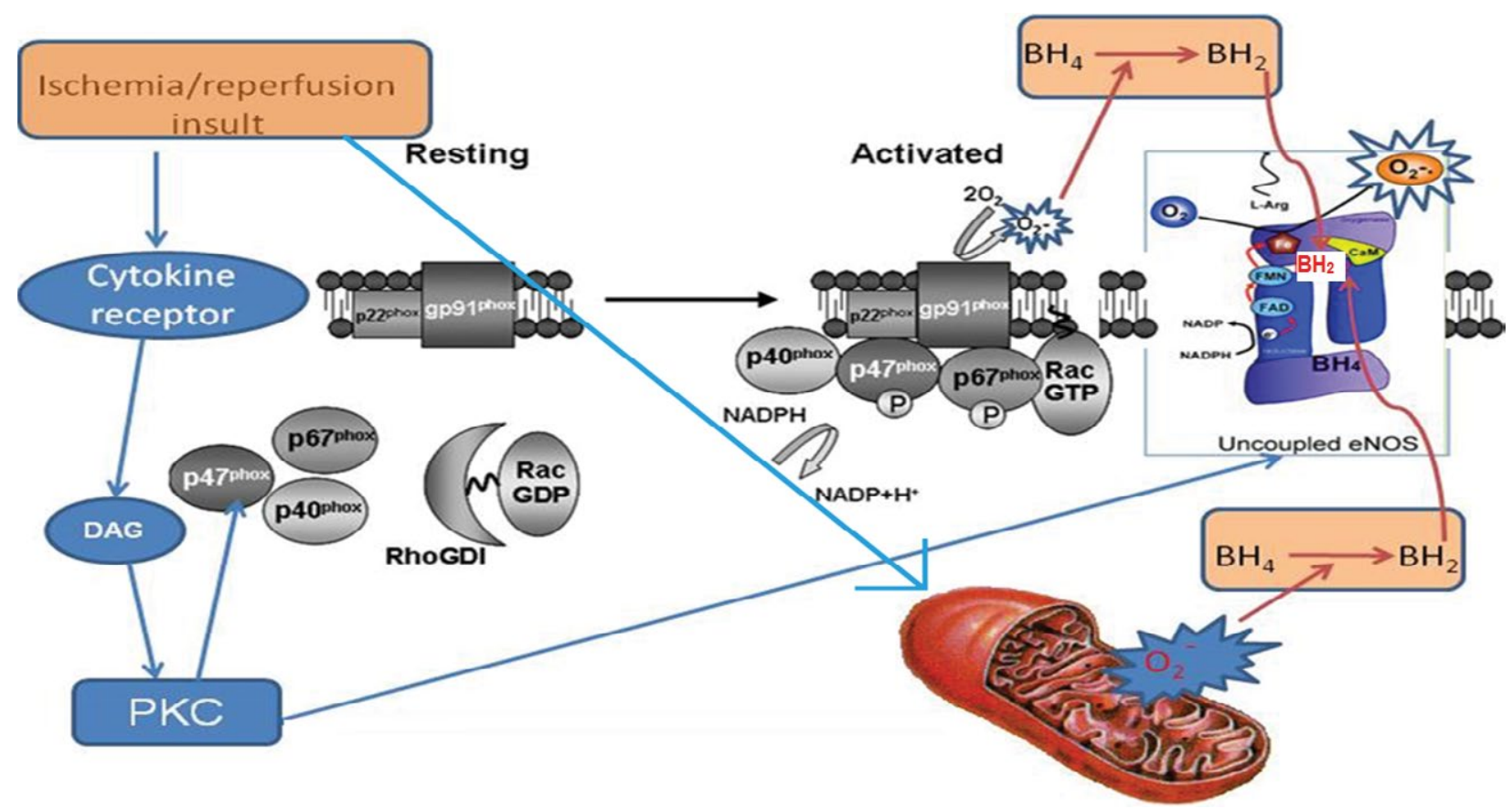

Figure 1: Ischemia/reperfusion insults leads to mitochondria damage releasing $\mathrm{O}_{2}^{-}$to initiate the oxidation process of $\mathrm{BH}_{4}$ to $\mathrm{BH}_{2}$ causing the uncoupling of eNOS

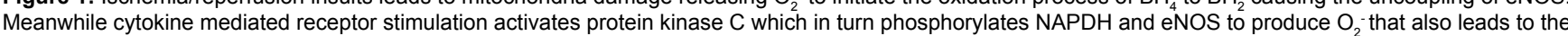
increase of oxidation of $\mathrm{BH}_{4}$ to $\mathrm{BH}_{2}$ causing more uncoupling of eNOS. Collectively these sources of reactive oxygen species reduce the amount of nitric oxide available. Modified from Wilkinson et al. and Schmidt and Alp $[15,38]$. 
Citation: Chen Q, Parker WC, Devine I, Ondrasik R, Habtamu T, et al. (2016) Apocynin Exerts Dose-Dependent Cardioprotective Effects by Attenuating Reactive Oxygen Species in Ischemia/Reperfusion. Cardiovasc Pharm Open Access 5: 176. doi:10.4176/2329-6607.1000176

Page 3 of 7

Chemical), $40 \mu \mathrm{M}, 400 \mu \mathrm{M}$, or $1 \mathrm{mM}$, respectively, for $15 \mathrm{~min}$ at $37^{\circ} \mathrm{C}$ in spectrophotometric cells. The PMNs were stimulated with $1 \mu \mathrm{M}$ $\mathrm{N}$-formyl-L-methionyl-L-leucyl-L-phenylalanine ( $\mathrm{MLL}, \mathrm{MW}=437$ $\mathrm{g} / \mathrm{mol}$; Calbiochem) in a final reaction volume of $1.0 \mathrm{ml}$. Absorbance at $550 \mathrm{~nm}$ was measured every $30 \mathrm{sec}$ for up to $90 \mathrm{sec}$ for fMLP (peak response), and the change in absorbance (SO release) from PMNs was determined relative to time 0 . The dose-response curve of apocynin on PMN SO release was used to determine a dose range that may be effective in myocardial ischemia/reperfusion experiments.

\section{Isolated rat heart preparation}

SD rats were injected with pentobarbital sodium $60 \mathrm{mg} / \mathrm{kg}$ and sodium heparin (1,000 U) Intra peritoneally (I.P.); after which the hearts were rapidly excised. The plasma was collected from the abdominal aorta of the same rat from which the heart was isolated for each cardiac perfusion experiment in order to be used infusion at the beginning of reperfusion [24]. The isolated rat heart was cannulated via the aorta onto a perfusion needle and immersed in a water-jacketed reservoir that contained $160 \mathrm{ml}$ of Krebs' buffer. The hearts were perfused with a modified Krebs' buffer (in mmol/l: 17.0 dextrose, $120.0 \mathrm{NaCl}, 25.0$ $\mathrm{NaHCO}_{3}, 2.5 \mathrm{CaCl}_{2}, 0.5$ EDTA, $5.9 \mathrm{KCl}$, and $1.2 \mathrm{MgCl}_{2}$ ) maintained at $37^{\circ} \mathrm{C}$ at a constant pressure of $80 \mathrm{mmHg}$ and aerated with $95 \% \mathrm{O}_{2}-5 \%$ $\mathrm{CO}_{2}$ to keep the $\mathrm{pH}$ at 7.3-7.4. A side arm in the perfusion line proximal to the heart inflow cannula allowed infusion of plasma (control hearts) or plasma containing apocynin $(40 \mu \mathrm{M}, 400 \mu \mathrm{M}$ and $1 \mathrm{mM})$. Coronary flow was monitored by a flowmeter (T106, Transonic Systems, Inc., Ithaca, NY). Left ventricular developed pressure, which is the left ventricular end-systolic pressure minus left ventricular end-diastolic pressure, the maximal and minimal rate of left ventricular developed pressure $\left(+\mathrm{dP} / \mathrm{dt}_{\text {max }}\right.$ and $-\mathrm{dP} / \mathrm{dt}_{\text {min }}$, respectively) and heart rate were monitored using a pressure transducer (SPR-524, Millar Instruments, Inc., Houston, TX) positioned in the left ventricular cavity and recorded using a Powerlab Station acquisition system (ADInstruments, Grand Junction, CO). Coronary flow, left ventricular developed pressure, $+\mathrm{dP} / \mathrm{dt}_{\max },-\mathrm{dP} / \mathrm{dt}_{\min }$ and heart rate were measured every $5 \mathrm{~min}$ for $15 \mathrm{~min}$ to obtain baseline measurements. After baseline, global ischemia was induced for $30 \mathrm{~min}$ by stopping the flow of Krebs' buffer. Hearts were infused at the beginning of reperfusion with plasma or plasma containing apocynin at a rate of $1 \mathrm{ml} / \mathrm{min}$ for $5 \mathrm{~min}$. Data continued to be recorded every $5 \mathrm{~min}$ for the $45 \mathrm{~min}$ reperfusion. At the end of the experiment, the infarct area and area-at-risk (i.e. entire heart) was visualized and measured by treating the tissue with $1 \%$ 2,3,5-triphenyltetazolium (TTC), as previously described [25].

\section{Hind limb ischemia/reperfusion in vivo procedure}

We measured blood $\mathrm{H}_{2} \mathrm{O}_{2} / \mathrm{NO}$ release in real-time from sensors placed in the femoral veins of male SD rats anesthetized with sodium pentobarbital $(60 \mathrm{mg} / \mathrm{kg}$, I.P. for induction and $30 \mathrm{mg} / \mathrm{kg} \mathrm{IP}$ for maintenance). Thereafter, one limb was subjected to ischemia/ reperfusion, while the other limb was used as a non-ischemic sham control in the same rat. The $\mathrm{H}_{2} \mathrm{O}_{2}$ or NO microsensors $(100 \mu \mathrm{m}$, World Precision Instruments [WPI] Inc., Sarasota, FL) were connected to a free radical analyzer (Apollo 4000, WPI Inc.) and inserted into a 24 gauge catheter placed inside each femoral vein, as previously described by Perkins et al. [8] and reviewed by Young et al. [26]. Ischemia in one hind limb was induced by clamping the femoral artery/vein for $20 \mathrm{~min}$ followed by $45 \mathrm{~min}$ of reperfusion. Apocynin $(13.7 \mathrm{mg} / \mathrm{kg}$ prepared in saline; $\sim 1 \mathrm{mM}$ in blood) or saline (non-drug control group) was administered at the beginning of reperfusion as a bolus via the jugular vein. We continuously recorded and collected the $\mathrm{H}_{2} \mathrm{O}_{2}$ or NO release data at $5 \mathrm{~min}$ intervals during a $15 \mathrm{~min}$ baseline, $20 \mathrm{~min}$ ischemia and 45 min reperfusion. The changes in $\mathrm{H}_{2} \mathrm{O}_{2}$ or $\mathrm{NO}$ release (in $\mathrm{pA}$ ) during ischemia/reperfusion are expressed as relative change to baseline (initial) readings. Thereafter, the values were converted to the concentration of $\mathrm{H}_{2} \mathrm{O}_{2}(\mu \mathrm{M})$ or $\mathrm{NO}(\mathrm{nM})$ after correction to the respective calibration curves. The values recorded from the femoral vein of the ischemia/reperfusion limb were subtracted from the values of the sham limb to yield a net difference and were recorded every 5 min continuously on time course graphs.

\section{Statistical analysis}

All data in the text and figures are presented as means \pm S.E.M. The data were analyzed by analysis of variance using post hoc analysis with the Student-Newman-Keuls test for PMN SO release and cardiac function/infarct size/area-at-risk and Student's t-test for the hindlimb ischemia/reperfusion data. Probability values of $\leq 0.05$ are considered to be statistically significant.

\section{Results}

\section{Apocynin dose-dependently decreased fMLP-induced PMN SO release}

PMNs release SO principally by activating NADPH oxidase. fMLP peptide activates PMN chemotactic receptor to generate the second messengers $\mathrm{Ca}^{++}$and DAG that activates protein kinase $\mathrm{C}$ isoforms to phosphorylate serine residues on $\mathrm{p} 47^{\text {phox }}$ to promote NADPH oxidase assembly at the PMN membrane to generate SO release (Figure 1). We found that apocynin exhibited dose-dependent reduction in fMLPstimulated PMN SO release (Figure 3). Apocynin at $40 \mu \mathrm{M}$ had no effect on PMN SO, whereas $400 \mu \mathrm{M}$ and $1 \mathrm{mM}$ significantly inhibited this response by $64 \pm 7$ and $87 \pm 7 \%$, respectively. The data generated from this assay was used to test a similar dose range of apocynin in the isolated rat heart ischemia/reperfusion experiments.

\section{Apocynin attenuated post-reperfused cardiac dysfunction and infarct size and area-at-risk}

Apocynin given at reperfusion significantly does-dependently attenuated ischemia/reperfusion induced cardiac contractile dysfunction and improved post-reperfused left ventricular developed pressure to $60 \pm 6 \%(40 \mu \mathrm{M} ; \mathrm{p}<0.05)$ and $74 \pm 3.6 \%(400 \mu \mathrm{M} ; \mathrm{p}<0.01)$ and $66 \pm 3.6 \%(1 \mathrm{mM} ; \mathrm{p}<0.01)$ of baseline at $45 \mathrm{~min}$ post-reperfusion compared to control ischemia/reperfusion hearts that only recovered to $47 \pm 5 \%$ of baseline values for left ventricular developed pressure (Table 1). Apocynin ( $400 \mu \mathrm{M}$ and $1 \mathrm{mM})$ significantly reduced post-

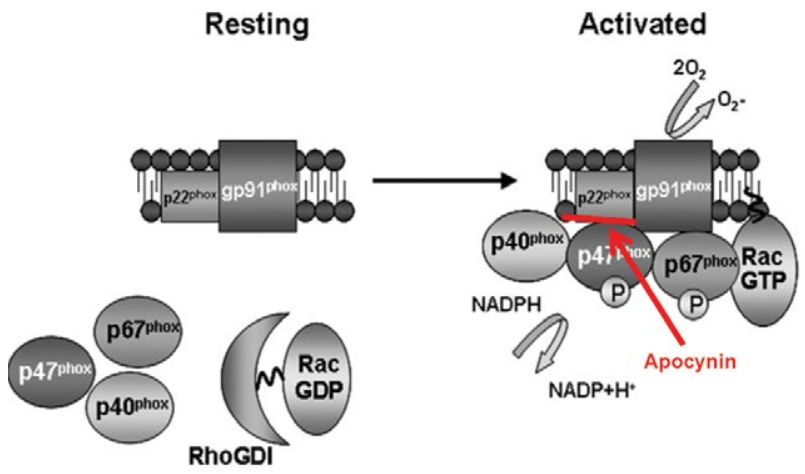

Figure 2: Schematic showing the inactive and active forms of NADPH oxidase. Red-line denotes the area of inhibition performed by apocynin. Adapted from Wilkinson et al. [38]. 
Citation: Chen Q, Parker WC, Devine I, Ondrasik R, Habtamu T, et al. (2016) Apocynin Exerts Dose-Dependent Cardioprotective Effects by Attenuating Reactive Oxygen Species in Ischemia/Reperfusion. Cardiovasc Pharm Open Access 5: 176. doi:10.4176/2329-6607.1000176

Page 4 of 7

\begin{tabular}{|c|c|c|c|c|}
\hline Cardiac Parameters & Control I/R (n = 13) & $\begin{array}{c}\mathrm{I} / \mathrm{R}+\underset{\mathrm{apocynin}}{(\mathrm{n}=9)} \mathbf{4 0} \mu \mathrm{M} \\
\end{array}$ & $\begin{array}{c}\mathrm{I} / \mathrm{R}+\underset{(\mathrm{n}=15)}{\operatorname{apocynin}} 400 \mu \mathrm{M} \\
\end{array}$ & $\begin{array}{c}\mathrm{I} / \mathrm{R}+\underset{(\mathrm{n}=10)}{\operatorname{apocynin}} 1 \mathrm{mM} \\
\end{array}$ \\
\hline Initial LVDP (mmHg) & $87 \pm 3.7$ & $92 \pm 3.1$ & $92 \pm 3.1$ & $94 \pm 3.4$ \\
\hline Final LVDP (mmHg) & $41 \pm 4.6$ & $55 \pm 6^{*}$ & $68 \pm 3.4^{* *}$ & $62 \pm 3.4^{* *}$ \\
\hline Initial LVESP (mmHg) & $98 \pm 3.9$ & $105 \pm 3.2$ & $103 \pm 3.5$ & $104 \pm 3.8$ \\
\hline Final LVESP (mmHg) & $101 \pm 5.8$ & $111 \pm 6.4$ & $111 \pm 4$ & $111 \pm 4.6$ \\
\hline Initial LVEDP (mmHg) & $11 \pm 0.6$ & $14 \pm 0.7$ & $11 \pm 0.8$ & $10 \pm 0.9$ \\
\hline Final LVEDP $(\mathrm{mmHg})$ & $60 \pm 5.2$ & $56 \pm 4.8$ & $43 \pm 3.8^{* *}$ & $48 \pm 4.9^{*}$ \\
\hline Initial + dP/dt $\max _{\text {mmHg/sec })}$ & $2336 \pm 73$ & $2331 \pm 56$ & $2284 \pm 69$ & $2385 \pm 101$ \\
\hline Final $+\mathrm{dP} / \mathrm{dt}_{\max }(\mathrm{mmHg} / \mathrm{sec})$ & $882 \pm 104$ & $1121 \pm 135$ & $1446 \pm 89^{* *}$ & $1342 \pm 95^{\star \star}$ \\
\hline Initial dP/dt $t_{\min }(\mathrm{mmHg} / \mathrm{sec})$ & $-1554 \pm 72$ & $-1585 \pm 45$ & $-1585 \pm 68$ & $-1617 \pm 112$ \\
\hline Final dP/dt ${ }_{\min }(\mathrm{mmHg} / \mathrm{sec})$ & $-745 \pm 57$ & $-793 \pm 99$ & $-1091 \pm 58^{* *}$ & $-928 \pm 45$ \\
\hline Initial coronary flow (ml/min) & $16.5 \pm 1.3$ & $19.1 \pm .0 .9$ & $21 \pm 1.3$ & $17 \pm 1.5$ \\
\hline Final coronary flow (ml/min) & $7.8 \pm 0.57$ & $10.5 \pm 1.1$ & $11.8 \pm 1.4$ & $8.9 \pm 0.84$ \\
\hline Initial Heart Rate (BPM) & $279 \pm 14.3$ & $283 \pm 16.5$ & $273 \pm 6.7$ & $273 \pm 11.1$ \\
\hline Final Heart Rate (BPM) & $239 \pm 16.9$ & $259 \pm 13.1$ & $245 \pm 8.5$ & $239 \pm 9.6$ \\
\hline
\end{tabular}

${ }^{*} \mathrm{p}<0.05,{ }^{* *} \mathrm{p}<0.01$ versus control l/R final cardiac function parameters

$\mathrm{I} / \mathrm{R}=$ Ischemia/Reperfusion

LVDP = Left Ventricular Developed Pressure

LVESP $=$ Left Ventricular End-Systolic Pressure

LVEDP $=$ Left Ventricular End-Diastolic Pressure

Table 1: Cardiac function parameters among different experimental groups.

reperfused left ventricular end-diastolic pressure compared to control ischemia/reperfusion values by $17 \pm 3.8(\mathrm{p}<0.01)$ and $12 \pm 4.9 \mathrm{mmHg}$ $(\mathrm{p}<0.05)$. Whereas, apocynin $40 \mu \mathrm{M}$ did not significantly affect this parameter compared to ischemia/reperfusion controls (Table 1). Similarly, apocynin exhibited a dose-dependent effect on reducing infarct size/area-at-risk, as illustrated in Figure 4.

Other cardiac function parameters are illustrated in Table 1. Of interest, dose-dependent effects of apocynin were also observed for $+\mathrm{dP} / \mathrm{dt}_{\max }$. Specifically, apocynin improved post-reperfused $+\mathrm{dP} / \mathrm{dt}_{\max }$ by $48 \pm 6 \%(40 \mu \mathrm{M}), 63 \pm 4 \%(400 \mu \mathrm{M} ; \mathrm{p}<0.01)$, and $56 \pm 4 \%(1$ $\mathrm{mM} ; \mathrm{p}<0.01)$ at $45 \mathrm{~min}$ reperfusion compared to control ischemia/ reperfusion hearts that only recovered to $38 \pm 4 \%$. Sham hearts $(n=6)$ were not subjected to ischemia/reperfusion and maintained cardiac function parameters and flow by $>90 \%$ and had $<5 \%$ infarct size/areaat- risk throughout the experimental time-course (data not shown).

\section{Apocynin reduced blood $\mathrm{H}_{2} \mathrm{O}_{2}$ levels}

Apocynin given I.V. (13.7 mg/kg) at the beginning of reperfusion decreased $\mathrm{H}_{2} \mathrm{O}_{2}$ in hind limb ischemia/reperfusion models compared to saline controls (Figure 5). Specifically, in saline control trails, $\mathrm{H}_{2} \mathrm{O}_{2}$ peaked up to $2.5 \mu \mathrm{M}$ during the first $5 \mathrm{~min}$ of reperfusion. Thereafter, the levels of $\mathrm{H}_{2} \mathrm{O}_{2}$ dropped to $1 \mu \mathrm{M}$ in blood, a concentration that was maintained throughout the reperfusion period. By contrast, apocynintreated animals $\mathrm{H}_{2} \mathrm{O}_{2}$ had an increase to nearly $5 \mu \mathrm{M}$ during the first five minutes of reperfusion; however, the level decreased, up to 4-fold, compared to saline control trials throughout the experimental time course. Of note, the decreased $\mathrm{H}_{2} \mathrm{O}_{2}$ levels were significantly different compared to saline controls between 20 and $45 \mathrm{~min}$.

\section{Apocynin increased blood NO levels}

Apocynin given I.V. (13.7 mg/kg) at the beginning of reperfusion increased NO in hind limb ischemia/reperfusion models compared to saline controls (Figure 6). Blood NO levels in saline controls a brief transiently increased to $\sim 30 \mathrm{nM}$ during the first $5 \mathrm{~min}$ of reperfusion; however, the levels decreased to approximately $50 \mathrm{nM}$, compared to baseline, at the end of the experimental time course. Conversely, apocynin-treated animals' blood NO levels significantly increased to $\sim 180 \mathrm{nM}$, as compared to baseline, during the first $5 \mathrm{~min}$ of reperfusion. These levels quickly dropped to $\sim 50 \mathrm{nM}$ between 10 and 20 min post-reperfusion, but at 20 min post-reperfusion began to significantly rise to $\sim 130 \mathrm{nM}$ throughout the remainder of the reperfusion time period $(\mathrm{p}<0.05$ at $20 \mathrm{~min}$ and $\mathrm{p}<0.01$ from $25-45$ $\min )$.

\section{Discussion}

\section{Summary of findings}

The major findings of this study are as follows: 1 . Apocynin dosedependently attenuated fMLP-induced leukocyte SO release by 64 $\pm 7 \%$ and $87 \pm 7 \%$ at $400 \mu \mathrm{M}$ and $1 \mathrm{mM}$, compared to untreated controls ( $<<0.01) ; 2$. In isolated perfused hearts, apocynin attenuated infarct size/area-at-risk by $39 \pm 7 \%(40 \mu \mathrm{M}), 28 \pm 4 \%(400 \mu \mathrm{M} ; \mathrm{p}<0.01)$ and $29 \pm 6 \%(1 \mathrm{mMp}<0.01)$, compared to control ischemia/reperfusion hearts that had an infarct size/area-at-risk of $46 \pm 2 \%$; 3 . Apocynin decreased left ventricular end-diastolic pressure to $56 \pm 5 \%(40 \mu \mathrm{M})$ $43 \pm 4 \%(400 \mu \mathrm{M} ; \mathrm{p}<0.01)$ and $48 \pm 5 \%(1 \mathrm{mM} ; \mathrm{p}<0.05)$ compared

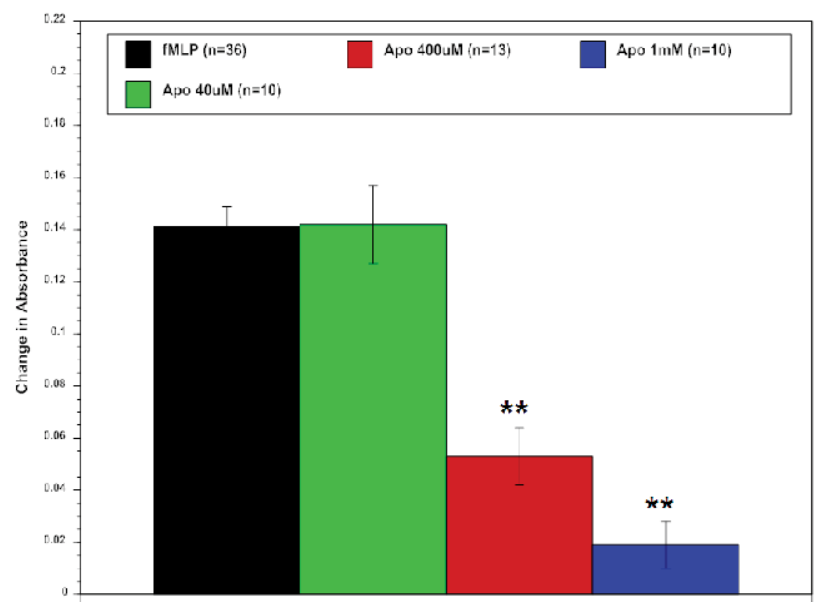

Figure 3: fMLP $(1 \mu \mathrm{M})$-induced $S O$ release in PMNs. The peak response in SO release $(90 \mathrm{sec})$. Apocynin (ApoC) $(400 \mu \mathrm{M}$ and $1 \mathrm{mM})$ significantly attenuated fMLP-induced SO release by $64 \pm 7 \%$ and $87 \pm 7 \%$, respectively, compared to $\mathrm{fMLP}\left({ }^{*} \mathrm{P}<0.01\right)$. 

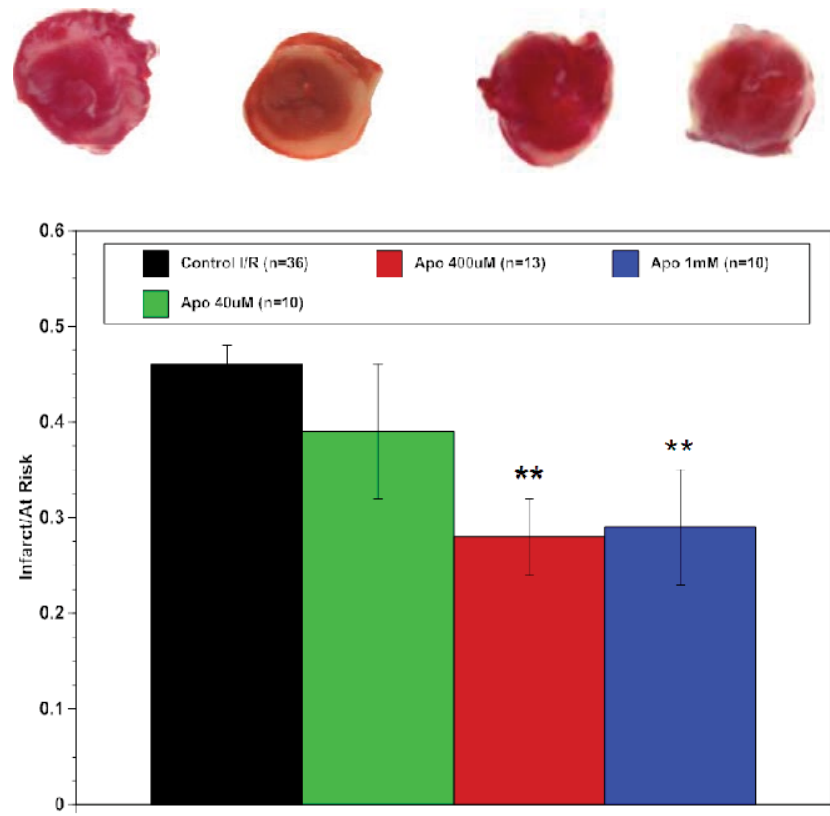

Figure 4: Representative heart sections of control ischemia/reperfusion, ischemia/reperfusion $+40 \mu \mathrm{M}, 400 \mu \mathrm{M}$ and $1 \mathrm{mM}$ apocynin subjected to TTC staining. Viable tissue is stained red while the infarcted tissue remained unstained (white). The graph shows the ratio of infarcted tissue weight to the total tissue weight. Dose-dependent apocynin treatment significantly decreased infarct size by $39 \pm 7 \%(40 \mu \mathrm{M}), 28 \pm 4 \%(400 \mu \mathrm{M})$ and $29 \pm 6 \%$ ( $\mathrm{mM}$ ) compared to untreated control myocardial ischemia/reperfusion hearts $\left({ }^{* *} p<0.01\right)$.

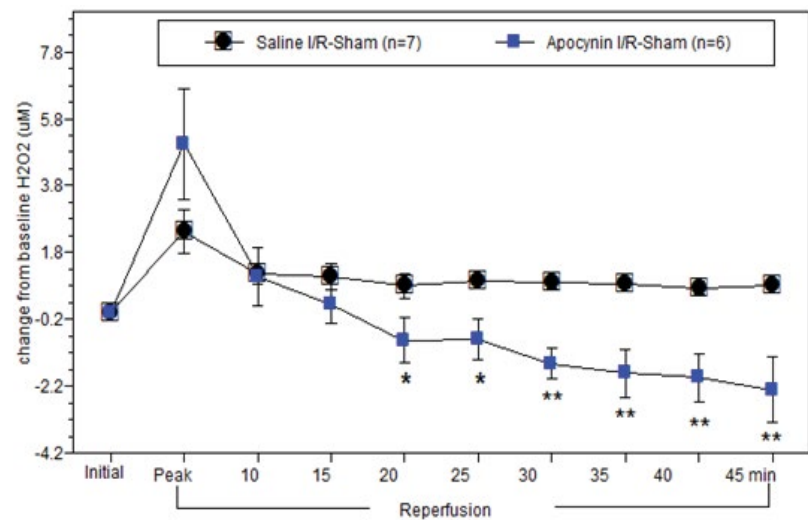

Figure 5: The relative difference in $\mathrm{H}_{2} \mathrm{O}_{2}$ release between ischemia/ reperfusion and sham femoral veins during reperfusion in anesthetized rats when given saline $(n=7)$ or apocynin $(13.7 \mathrm{mg} / \mathrm{kg} ; n=6)$. Apocynin treated rats showed a significant reduction in blood $\mathrm{H}_{2} \mathrm{O}_{2}$ release compared to salinetreated controls from 20 min to 45 min of reperfusion ( $\mathrm{*} p<0.05, " \mathrm{p}<0.01$ )

to control ischemia/reperfusion hearts that were $60 \pm 5 \%$; 4 . Apocynin significantly decreased blood $\mathrm{H}_{2} \mathrm{O}_{2}$ levels and increased blood NO by four-fold compared to saline controls at the end of reperfusion (both, $\mathrm{p}<0.01)$. These results suggest that apocynin exerted cardio protective effects by inhibiting reactive oxygen species release generated by NADPH oxidase during ischemia/reperfusion.

The role of NADPH oxidase and oxidative stress during ischemia/reperfusion

NADPH oxidase activity is increased in myocardial ischemia/ reperfusion in part through activation of TNFa receptors that in turn activate protein kinase $\mathrm{C}[20,27,28]$. Activated protein kinase $\mathrm{C}$ isoforms (e.g., alpha, beta II and zeta) phosphorylate serine residues on cytosolic $\mathrm{p} 47^{\text {phox }}$, which is primarily expressed in leukocytes and vascular endothelium, to promote assembly and activation of NADPH oxidase $[27,29]$ leading to the production of SO (Figure 1). It has been indicated that NADPH oxidase activation is the initial source of SO, that in part mediates mitochondrial potassium ATP channel opening and release of reactive oxygen species during angiotensin II induced preconditioning [30]. It is well-known that transient mitochondrial potassium ATP channel opening is important to induce preconditioning in the heart to reduce infarct size [31]. However, prolonged opening of this mitochondrial channel throughout prolonged ischemia (i.e., $30 \mathrm{~min}$ ) and during reperfusion does not reduce infarct size compared to untreated I/R controls [32]. Consequently, prolonged opening of mitochondria potassium ATP channels during ischemia and reperfusion may contribute to oxidative stress during ischemia/ reperfusion and in turn further oxidize $\mathrm{BH}_{4}$ to $\mathrm{BH}_{2}$ to promote eNOS uncoupling and further reactive oxygen species release (Figure 1).

Regarding NADPH oxidase and eNOS uncoupling, activation of Protein kinase C beta II isoform is mostly responsible for NADPH oxidase activation and inhibition of eNOS activity [23,33]. Our previous studies found that a selective PKC beta II peptide inhibitor significantly attenuated oxidative stress in hind limb I/R and restored post-reperfused cardiac function in isolated $\mathrm{I} / \mathrm{R}$ hearts $[23,33,34]$. Given that increased uncoupled eNOS activity facilities oxidative stress, the antioxidant and cardioprotective effects of Protein kinase $\mathrm{C}$ beta II inhibitor most likely are principally due to inhibition on $\mathrm{NADPH}$ oxidase effects which in turn would reduce oxidation of $\mathrm{BH}_{4}$ to $\mathrm{BH}_{2}$ and therefore attenuate uncoupled eNOS activity. Therefore, understanding vascular/cardiac NADPH oxidase during reperfusion following prolonged ischemia may disclose the triggering source of oxidative stress in reperfusion injury (Figure 1). Our in vivo and ex vivo hind limb and myocardial ischemia/reperfusion models will largely exclude the contribution of polymorphonuclear leukocyte NADPH oxidase because they are recruited into the reperfusion site after a few hours of reperfusion.

Apocynin is a selective NADPH oxidase inhibitor that works by blocking the association of $\mathrm{p} 47^{\text {phox }}$ with the membrane $\mathrm{p} 22^{\text {phox }}$ in endothelial cells and leukocytes [14,35] (Figure 1). Apocynin is considered to be a prodrug that is converted to diapocynin by endothelial peroxidase and leukocyte myeloperoxidase which then oxidizes cysteine-196 on $\mathrm{p} 47^{\text {phox }}$ and thereby inhibits NADPH oxidase assembly and activation [22]. P47 ${ }^{\text {phox }}$ is highly expressed in myeloid and vascular smooth muscle/endothelial cells [10]. Therefore, the primary target for apocynin would be attenuation of vascular NADPH oxidase during ischemia and early reperfusion since only resident PMNs would be present during this time. Mozaffari et al. [13] reported that apocynin $(100 \mu \mathrm{M})$ given during pre-ischemia improved $+\mathrm{dP} / \mathrm{dt}_{\max }$ and $+\mathrm{dP} /$ $\mathrm{dt}_{\text {min }}$ and decreased infarct size/area-at-risk compared to untreated controls in isolated perfused rat hearts subjected to $40 \mathrm{~min}$ regional ischemia followed by 2 hour reperfusion [13]. However, their study did not measure SO or $\mathrm{H}_{2} \mathrm{O}_{2}$ release in the post-reperfused tissue to assess the level of reactive oxygen species attenuation induced by apocynin to attribute a mechanism of action. Moreover, they did not give apocynin exclusively during reperfusion since pretreatment is not always a clinical option. Therefore, it is of high clinical importance to determine the degree of reactive oxygen species inhibition from NADPH oxidase and its relative contribution during the reperfusion phase of ischemia/reperfusion injury. Another study by Jiao et al. [36], 


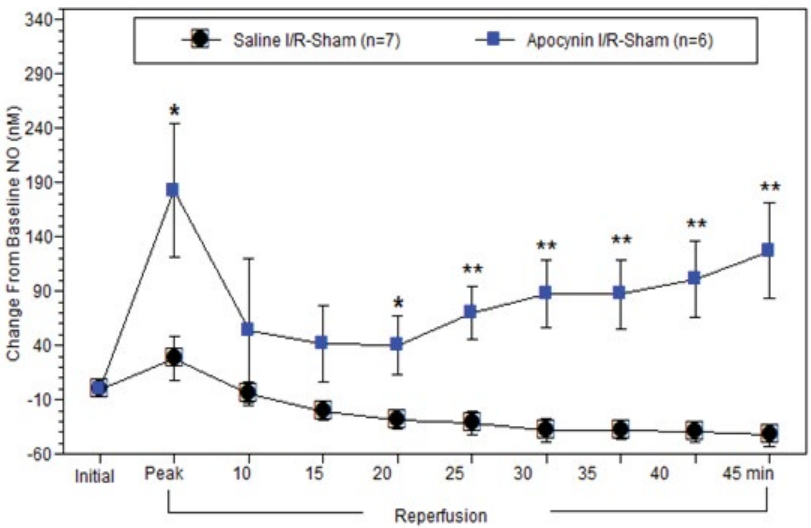

Figure 6: The relative difference in NO release between ischemia/ reperfusion and sham femoral veins during reperfusion in anesthetized rats when given saline $(n=7)$ or apocynin $(13.7 \mathrm{mg} / \mathrm{kg} ; \mathrm{n}=6)$. Apocynin treated rats showed a significant increase in blood NO release compared to salinetreated controls from 20 min to 45 min of reperfusion ( $p<0.05, " * p<0.01$ ).

reported that apocynin reduced SO in cardiac ischemia/reperfusion tissue, which was associated with a decrease in infarct size/area-atrisk compared to controls in mice subjected to regional ischemia for $30 \mathrm{~min}$ followed by 24 hour reperfusion and administered apocynin I.V. (5 mg/kg) $10 \mathrm{~min}$ prior to reperfusion. However, their study did not assess cardiac function or infarct size/area-at-risk, which may be associated with the decreased SO release [36]. Similarly, another study by Gao et al. [28] also performed regional ischemia in mice for $30 \mathrm{~min}$ followed by $90 \mathrm{~min}$ reperfusion and found that acetylcholine (Ach)induced vasodilatation in isolated coronary arterioles was improved in mice given apocynin I.V. ( $25 \mathrm{mg} / \mathrm{kg}$ ) prior to reperfusion. This effect was associated with decreased SO production [28]. Moreover, their study attributed the increased NADPH oxidase activity to increased TNFa released from vascular smooth muscle in myocardial ischemia/ reperfusion tissue. However, like the Jiao et al. study, Gao et al. study did not assess cardiac function or infarct size/area-at-risk.

Interestingly, apocynin at $1 \mathrm{mM}$ did not improve cardiac function, infarct size or area-at-risk compared to the $400 \mu \mathrm{M}$ dose. It is possible that apocynin exerted its maximal effect at $400 \mu \mathrm{M}$ in the isolated perfused heart study. In contrast, the SO release from leukocytes was inhibited to a greater extent at $1 \mathrm{mM}$ compared to $400 \mu \mathrm{M}$, suggesting that vascular and cardiac myocyte NADPH oxidase may have reached its maximal inhibition at $400 \mu \mathrm{M}$. It is also possible that the $1 \mathrm{mM}$ dose may have started to exert some paradoxical oxidative stress in the heart tissue.

According to Riganti et. al. [37], apocynin induced oxidative stress in a dose-dependent way in glial cells in vitro. Furthermore, high concentration apocynin incubated in cultured glial cells showed an increase in oxidative stress via measurements of lipid peroxidation, $\mathrm{H}_{2} \mathrm{O}_{2}$, and cytotoxic level. It should be emphasized that the concentration of apocynin used in the hindlimb ischemia/reperfusion model (i.e., $13.7 \mathrm{mg} / \mathrm{kg}$ ) approximated to a concentration of about $1 \mathrm{mM}$ in blood. However, given that apocynin is a small molecular compound that could be cleared by the kidneys, it is plausible that the effective dose was less in the blood over time since it took about 20 minutes for apocynin to exert significant effects on blood $\mathrm{H}_{2} \mathrm{O}_{2}$ levels and NO levels. Of interest, it should be noted that the initial increase in blood $\mathrm{H}_{2} \mathrm{O}_{2}$ and NO levels observed in both saline and apocynintreated animals is consistent with previous studies showing an initial increase in these levels, and may, in part, be due to the initiation of blood flow contacting the respective microsensor $[4,7,8]$. Subsequent measurements after this initial burst may more accurately represent the relative increase or decrease of the biomolecule being measured (i.e., $\mathrm{H}_{2} \mathrm{O}_{2}$ or $\mathrm{NO}$ ).

\section{Conclusion}

In summary, apocynin exerted cardio protective effects on postrefused cardiac function that paralleled a decrease in infarct size/areaat-risk. Moreover, the reduction of blood $\mathrm{H}_{2} \mathrm{O}_{2}$ release and increased NO bioavailability in the hind limb ischemia/reperfusion model suggests that apocynin exerted its cardio protective effects via the inhibition of SO release. Collectively, this study suggests that NADPH oxidase significantly contributes to reactive oxygen species production during ischemia/reperfusion and that inhibiting this production during reperfusion in effective to attenuate oxidative stress and subsequent cardiac cell death and cardiac contractile dysfunction. However, it is possible that the results of apocynin may in part be due to scavenging $\mathrm{H}_{2} \mathrm{O}_{2}$ in addition to selective inhibition of NADPH oxidase as suggested by Johnson et al. [35].

\section{Funding Sources}

Center for Chronic Diseases of Aging at P.C.O.M.

\section{Acknowledgement}

Stephanie Liu, Graduate Student at P.C.O.M., for assisting with editing of this manuscript.

\section{References}

1. Roger VL, Go AS, Lloyd-Jones DM, Adams RJ, Berry JD, et al. (2011) Heart disease and stroke statistics-2011 update: a report from the American Heart Association. Circulation 123: e18-e209.

2. Hausenloy DJ, Yellon DM (2013) Myocardial ischemia-reperfusion injury: a neglected therapeutic target. J Clin Invest 123: 92-100.

3. Lefer AM, Lefer DJ (1996) The role of nitric oxide and cell adhesion molecules on the microcirculation in ischaemia-reperfusion. Cardiovasc Res 32: 743-751.

4. Chen Q, Kim EE, Elio K, Zambrano C, Krass S, et al. (2010) The role of tetrahydrobiopterin and dihydrobiopterin in ischemia/reperfusion injury when given at reperfusion. Adv Pharmacol Sci 2010: 963914.

5. Tsao PS, Aoki N, Lefer DJ, Johnson G Lefer AM (1990) Time course of endothelial dysfunction and myocardial injury during myocardial ischemia and reperfusion in the cat. Circulation 82: 1402-1412.

6. Hayward R, Lefer AM (1998) Time course of endothelial-neutrophil interaction in splanchnic artery ischemia-reperfusion. Am J Physiol 275: H2080-2086.

7. Teng JC, Kay H, Chen Q, Adams JS, Grilli C, et al. (2008) Mechanisms related to the cardioprotective effects of protein kinase $\mathrm{C}$ epsilon (PKC epsilon) peptide activator or inhibitor in rat ischemia/reperfusion injury. Naunyn Schmiedebergs Arch Pharmacol 378: 1-15.

8. Perkins KA, Pershad S, Chen Q, McGraw S, Adams JS, et al. (2012) The effects of modulating eNOS activity and coupling in ischemia/reperfusion (I/R) Naunyn Schmiedebergs Arch Pharmacol 385: 27-38.

9. Schramm A, Matusik P, Osmenda G, Guzik TJ (2012) Targeting NADPH oxidases in vascular pharmacology. Vascul Pharmacol 56: 216-231.

10. Bedard K, Krause KH (2007) The NOX family of ROS-generating NADPH oxidases: physiology and pathophysiology. Physiol Rev 87: 245-313.

11. Ago T, Kuroda J, Kamouchi M, Sadoshima J, Kitazono T (2011) Pathophysiological roles of NADPH oxidase/nox family proteins in the vascular system. Review and perspective. Circ J 75: 1791-1800.

12. Doughan AK, Harrison DG, Dikalov SI (2008) Molecular mechanisms of angiotensin II-mediated mitochondrial dysfunction: linking mitochondrial oxidative damage and vascular endothelial dysfunction. Circ Res 102: 488-496.

13. Mozaffari MS, Baban B, Liu JY, Abebe W, Sullivan JC, et al. (2011) Mitochondrial complex I and NAD(P)H oxidase are major sources of exacerbated oxidative stress in pressure-overloaded ischemic-reperfused hearts. Basic Res Cardio 106: $287-297$. 
Citation: Chen Q, Parker WC, Devine I, Ondrasik R, Habtamu T, et al. (2016) Apocynin Exerts Dose-Dependent Cardioprotective Effects by Attenuating Reactive Oxygen Species in Ischemia/Reperfusion. Cardiovasc Pharm Open Access 5: 176. doi:10.4176/2329-6607.1000176

Page 7 of 7

14. Kleniewska P, Piechota A, Skibska B, Gorąca A (2012) The NADPH oxidase family and its inhibitors. Arch Immunol Ther Exp (Warsz) 60: 277-294.

15. Schmidt TS, Alp NJ (2007) Mechanisms for the role of tetrahydrobiopterin in endothelial function and vascular disease. Clin Sci (Lond) 113: 47-63.

16. Vasquez-Vivar J, Martásek P, Whitsett J, Joseph J, Kalyanaraman B (2002) The ratio between tetrahydrobiopterin and oxidized tetrahydrobiopterin analogues controls superoxide release from endothelial nitric oxide synthase: an EPR spin trapping study. Biochem J 362: 733-739.

17. Duda M, Konior A, Klemenska E, Beresewicz A (2007) Preconditioning protects endothelium by preventing ET-1-induced activation of NADPH oxidase and xanthine oxidase in post-ischemic heart. J Mol Cell Cardiol 42: 400-410.

18. Fabian RH, Perez-Polo JR, Kent TA (2008) Perivascular nitric oxide and superoxide in neonatal cerebral hypoxia-ischemia. Am J Physiol Heart Circ Physiol 295: H1809-1814.

19. Nolly MB, Caldiz CI, Yeves AM, Villa-Abrille MC, Morgan PE, et al. (2014) The signaling pathway for aldosterone-induced mitochondrial production of superoxide anion in the myocardium. J Mol Cell Cardiol 67: 60-68.

20. Frangogiannis NG, Perrard JL, Mendoza LH, Burns AR, Lindsey ML, et al. (1998) Stem cell factor induction is associated with mast cell accumulation after canine myocardial ischemia and reperfusion. Circulation 98: 687-698.

21. Stefanski J and Pawliczak R (2008) Apocynin: Molecular Aptitudes. Mediators of Inflammation 1-10

22. Mora-Pale M, Kwon SJ, Linhardt RJ, Dordick JS (2012) Trimer hydroxylated quinine derived from apocynin targets cysteine residues of $\mathrm{p} 47 \mathrm{phox}$ preventing the activation of human vascular NADPH oxidase." Free Radic Biol Med 52 962-969.

23. Omiyi D, Brue RJ, Taormina P 2nd, Harvey M, Atkinson N, et al. (2005) Protein kinase $C$ betall peptide inhibitor exerts cardioprotective effects in rat cardiac ischemia/reperfusion injury. J Pharmacol Exp Ther 314: 542-551.

24. Peterman EE, Taormina P 2nd, Harvey M, Young LH (2004) Gö 6983 exerts cardioprotective effects in myocardial ischemia/reperfusion. J Cardiovasc Pharmacol 43: 645-656.

25. Blakeman N, Qian Chen, Jasmine Tolson, Brian Rueter, Brian Diaz, et al. (2012) Triacsin C, a fatty acyl coA synthetase inhibitor, improves cardiac performance following global ischemia. American Journal of Biomedical Sciences 4: 249261

26. Young LH, Qian Chen, Margaret T Weis (2011) Direct Measurement of Hydrogen Peroxide $(\mathrm{H} 2 \mathrm{O} 2)$ or Nitric Oxide (NO) Release: A Powerful Tool to Assess Real-time Free Radical Production in Biological Models. Am J BioMed Sci 3: 40-49

27. Young LH, Balin BJ, Weis MT (2005) Gö 6983: a fast acting protein kinase
C inhibitor that attenuates myocardial ischemia/reperfusion injury. Cardiovasc Drug Rev 23: 255-272.

28. Gao Y, Fang X, Tong Y, Liu Y, Zhang B (2009) TLR4-mediated MyD88 dependent signaling pathway is activated by cerebral ischemia-reperfusion in cortex in mice. Biomed Pharmacother 63: 442-450.

29. Yu J, Weïwer M, Linhardt RJ, Dordick JS (2008) The role of the methoxyphenol apocynin, a vascular NADPH oxidase inhibitor, as a chemopreventative agent in the potential treatment of cardiovascular diseases. Curr Vasc Pharmacol 6 204-217.

30. Raval AP, Dave KR, DeFazio RA, Perez-Pinzon MA (2007) epsilonPKC phosphorylates the mitochondrial $\mathrm{K}(+)$ (ATP) channel during induction of ischemic preconditioning in the rat hippocampus. Brain Res 1184: 345-353.

31. Garlid KD, Dos Santos P, Xie ZJ, Costa AD, Paucek P (2003) Mitochondrial potassium transport: the role of the mitochondrial ATP-sensitive $\mathrm{K}(+)$ channel in cardiac function and cardioprotection. Biochim Biophys Acta 1606: 1-21.

32. Pomerantz BJ, Thomas N Robinson, Julie K Heimbach, Casey M Calkins, Stephanie A Miller, et al. (2000) Selective mitochondrial KATP channel opening controls human myocardial preconditioning: too much of a good thing? Surgery 128: $368-373$.

33. Korchak HM, Kilpatrick LE (2001) Roles for beta II-protein kinase C and RACK1 in positive and negative signaling for superoxide anion generation in differentiated HL60 cells. J Biol Chem 276: 8910-8917.

34. Chen Q, Brian Rueter, Samuel Krass, Christopher Zambrano, Shawn Thomas et al. (2010) The potential clinical application of protein kinase C beta II peptide inhibitor and Gö 6983 in vascular endothelial dysfunction. Curr Topics Pharmacol 14: 11-24.

35. Johnson DK, Schillinger KJ, Kwait DM, Hughes CV, McNamara EJ, et al. (2002) Inhibition of NADPH oxidase activation in endothelial cells by orthomethoxy-substituted catechols. Endothelium 9: 191-203.

36. Jiao XY, Gao E, Yuan Y, Wang Y, Lau WB, et al. (2009) INO-4885 [5,10,15,20-tetra[N-(benzyl-4'-carboxylate)-2-pyridinium]-21H,23H-porphine iron(III) chloride], a peroxynitrite decomposition catalyst, protects the hear against reperfusion injury in mice. J Pharmacol Exp Ther 328: 777-784.

37. Riganti C, Costamagna C, Bosia A, Ghigo D (2006) The NADPH oxidase inhibitor apocynin (acetovanillone) induces oxidative stress. Toxicol Appl Pharmacol 212: 179-187.

38. Wilkinson BL, Landreth GE (2006) The microglial NADPH oxidase complex as a source of oxidative stress in Alzheimer's disease. J Neuroinflammation 3: 30 